\title{
Islamic Ethics of Waste Management towards Sustainable Environmental Health
}

\author{
Suhaila Mohd Omar , Ahmed Jalal Khan Chowdhury \& Abdurezak Abdulahi Hashi \\ Department of Biotechnology, Kulliyyah of Science, International Islamic University Malaysia, Jalan Sultan \\ Ahmad Shah, Bandar Indera Mahkota, 25200 Kuantan, Pahang
}

\begin{abstract}
Islam is a religion that prescribes a way of life that goes beyond the rituals. It provides a holistic guide to human beings in almost every aspect of life in this world. However, the modernization and economic growth have taken the leads in the society governance and therefore tarnished some of the Muslim society's perceptions on the holistic guidance of Islamic teachings. One of the consequences was readily displayed through attitudes and inefficient waste management practice of the majority of the Islamic country that lead to the environmental health problem. The paper discusses the existing waste management practice and positive roles of true Islamic understanding through the Qur'an and the Sunnah in terms of avoiding wasteful consumption and manners of cleanliness to resolve global environmental health problem caused by poor waste management.
\end{abstract}

KEYWORDS: waste management, cleanliness, environmental health, and values

\section{INTRODUCTION}

Waste may consist of the unwanted materials left over from a manufacturing process (industrial, commercial, mining or agricultural operations,) or from community and household activities. The material may be discarded or accumulated, stored, or treated (physically, chemically, or biologically), prior to being discarded or recycled. As for Malaysia, the Solid Waste and Public Cleansing Management Act 2007 defined solid waste as any scrap material or other unwanted surplus substance or rejected products that arise as a result of human activity, but excluding scheduled wastes, sewage and radioactive wastes. 1 Solid waste management includes all activities involved from the generation towards the final waste disposal such as minimization, storage, collection, transfer and transportation, treatment and landfill disposal. Ideally, these activities are planned to be consistent with the best practice of public and environmental health, economics, engineering, administration and legal consideration.

Previously, waste was not a threat, until the urban population boomed and the classical approaches which were just concerned about removing human faeces, food waste or any breading media for flies and rats, out of sight either by burning or dumping in the remote area obviously are no longer relevant. For example, the annual generation of municipal solid waste (MSW) in Malaysia has approximately exceeded 28000 tonnes/day in recent years, ${ }^{2}$ almost reaching the 30,000 tonnes/day, the estimated amount predicted in $2020 .^{3}$ The figure showed more than $100 \%$ increase compared to the amount of

Suhaila Mohd Omar

Department of Biotechnology,

Kulliyyah of Science,

International Islamic University Malaysia,

Kuantan Campus.

Email: osuhaila@iium.edu.my waste generated in 1996, which was 13000 tonnes/day. Therefore the increase of waste generation has resulted in an urgent need for a more efficient and sustainable waste management system in the country. The failure to do so will cause continuous pollution of the environment and will influence human health and the spread of diseases.

\section{Wasteful consumption}

At the moment, it is estimated that approximately 1.3 billion tonnes of MSW are generated globally every year and are expected to increase to approximately 2.2 billion tonnes per year by $2025 .^{4}$ MSW generation rates were influenced by population growth, urbanization, economic development, the degree of industrialization, living standards, public habits, and local climate. ${ }^{2,4,5}$ In fact, the amount of waste produced per person per day also depends on the economic status of the community concerned. ${ }^{5}$ The rates of MSW growth are fastest in China, other parts of East Asia, and parts of Eastern Europe and the Middle East. ${ }^{4}$

Overall, as illustrated in Figure 1 , the main component of the global MSW stream consists of organic waste $(46 \%)$, followed by paper $(17 \%)$, plastic $(10 \%)$, glass $(5 \%)$, metal $(4 \%)$ and others $(18 \%) .{ }^{4}$ Solid waste management authorities throughout the world used similar classification for the waste component, but the proportion of each component differs according to the respective countries and could be affected by local culture. For example, rapid urbanization and high growth domestic product (GDP) growth had contributed to the high amount of waste produced in China. Interestingly, in comparison to the other highincome countries, the content of organic waste in China is $55.86 \%,{ }^{6}$ which is two times higher than Japan (26\%) and USA (25\%). In Saudi Arabia, food 
made up about $37 \%$ of the waste composition, followed by paper $28.5 \%$, plastic $(5.2 \%)$, glass $(4.6 \%)$ and others. The waste generation is affected by the extensive use of food, paper, packaging and massive use of disposable plastic stuff, especially during the visit of a large number of pilgrims every year. ${ }^{7}$ Food waste also made up $60 \%$ of the 7.34 million tons of Malaysia generated waste in $2005^{8}$ and currently shows consistent alarming trend. ${ }^{9}$

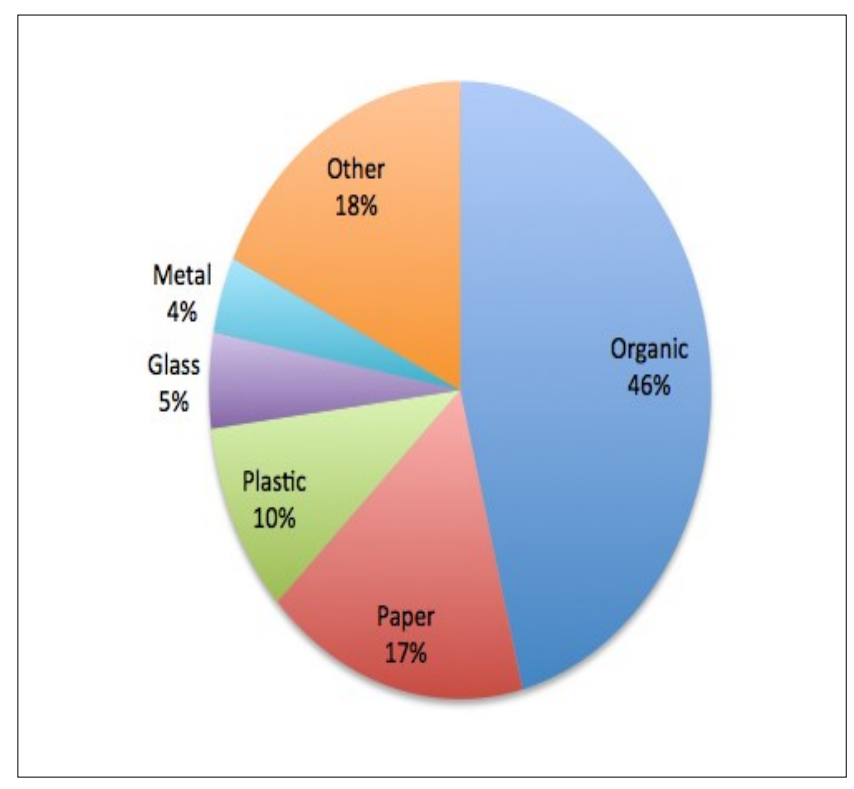

Figure 1: Global solid waste composition in percentage (\%) [4].

While hazardous wastes were normally managed separately from municipal solid waste, these types of waste still present in the MSW stream, originated from household consumption such as batteries, paint, and waste from electric and electronic devices (e-waste). Approximately 20-25 million tonnes of e-waste were generated globally. ${ }^{10}$ The rapid evolution of the electric and electronic industry such as computer and smartphone, reduce their lifespan and causing the early obsolescence of many electrical and electronic devices and potentially resulting in e-waste escalation. ${ }^{1,11}$ For instance, television and computer monitors normally contain hazardous materials such as lead, mercury, and cadmium, while nickel, beryllium, and zinc can often be found in circuit boards. ${ }^{11}$ Some of the ewaste generated in developed countries end up in the recycling centre of developing countries that are economically challenged and lack of the infrastructure for proper e-waste management resulting in adverse economic, social and environmental impact. ${ }^{1,11}$

\section{Impact of Improper Waste Management Practices Towards Environmental Health}

The waste management hierarchy is a preferential order of waste management options that aims to reduce environmental impacts by prioritizing prevention, reduction, reuse, recycling, and recovery over landfill. ${ }^{12}$ It has received wide support in most developed countries as a guide for waste management ${ }^{13}$ especially in term of diversion from ultimate waste disposal in a landfill (Figure 2). The aims of the hierarchy coincide largely with those of Islamic ethics, which promote unwasteful and less negative impact towards human and environment.

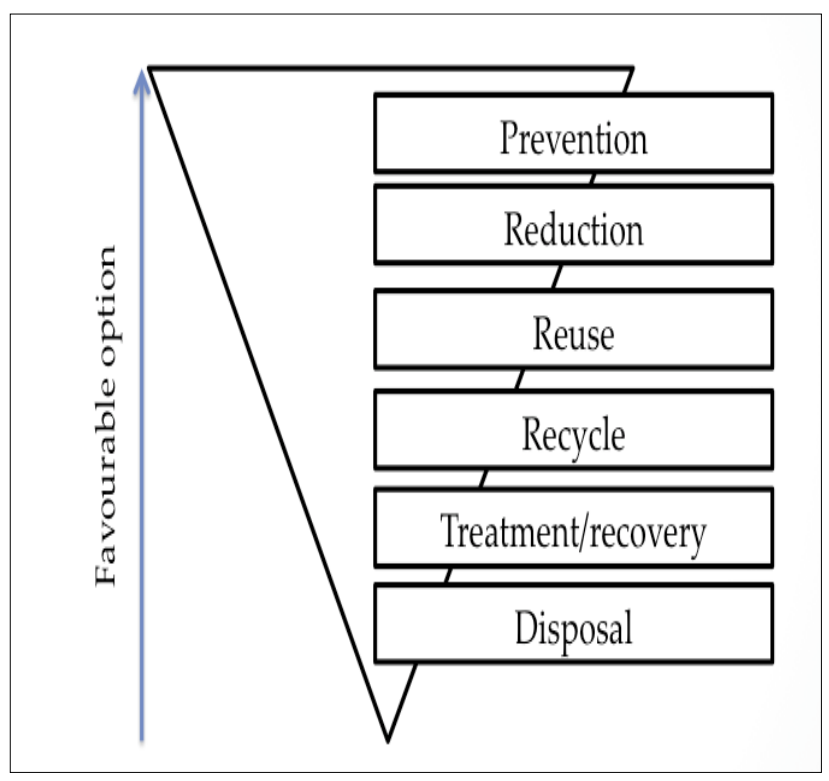

Figure 2: Waste management hierarchy

However, the current practice of waste management especially in developing countries is more restricted to disposal in the landfill or worse, disposal in the waterways or dump. In comparison to the sanitary landfill, which has liner, leachate, and gas management system, as well as a better control of public access, a dump was basically vice versa. The biodegradation of waste will produce leachate, which, if not properly treated will cause serious surface and ground water contamination. As waste is a complex mixture of different substances, which some of them are intrinsically hazardous to health such as unconsumed medications, toxic chemicals from the local industry (e.g., tannery industry) and heavy metals, it could easily pollute the groundwater and waterways hence accumulated in the food chain. The impact will be greater to those nations that still depend on river water for daily consumption. One-grade deterioration in Chinese river water quality was found associated with a 9.7 percent increase in the incidence of digestive cancer. ${ }^{14}$ The exposures to the chemicals in the waterways were significantly and positively correlated with infant mortality (both neo-natal and post-natal) and their low birth-weight. ${ }^{15}$ Not to mention, the disposal of bulky or non-degradable waste products such as household furniture, plastics, and fabrics in waterways that could lead to blockage of the drainage system and cause a flash 
flood or worsened the flood impact. Plastic debris was consumed and entangled sea creatures to death. ${ }^{16}$ Furthermore, problems such as odours, litter, noise, heavy traffic and vector diseases are among less easily quantifiable hazards, which might impact the population that lives near a waste disposal site. Generally, there is a large workforce employed in waste collection, sorting and disposal, which may be exposed to chemical and biological hazards. The incidence of occupational accidents in waste collection workers has been found to be higher than the general workforce. It has been suggested that the increased exposure to bioaerosols and volatile compounds may lead to the elevated incidence of work-related respiratory, gastrointestinal and skin problems in waste collections compared to the other general workforce. $^{17}$

Incineration, a thermal treatment, is the common choice of waste treatment for hazardous and medical waste. Some developed countries such as Japan and Denmark used this technology for MSW treatment and coupled it with energy generation. The option is not a surprise since the composition of paper and plastic in these countries is higher than organic waste compared to developing countries. ${ }^{4}$ Incineration of wet organic wastes used up more fuel, hence more costly. The combustion of hazardous, medical and MSW produced pollutants that can be grouped as particles and gases, metals, and organic compounds. ${ }^{18}$ It is evident that ten pollutants considered to have the greatest potential impact on human health based on environmental persistence, bioaccumulation and amount emitted and/or on the inherent toxicity were cadmium, mercury, arsenic, chromium, nickel, dioxins, PCBs, PAHs, PM10 and SO2. ${ }^{19}$ The organic compounds that have received the most attention relating to incineration are dioxins and PCBs, partly because of their ability to accumulate in the body.

There is an urgent demand to modernize the solid waste management system, particularly in developing nations through the application of the $3 R s$ (reduce, reuse and recycle) in order to minimize the amount of waste that will end up in the incinerators and landfill. Recycling is the most widely adapted strategy due to its simple procedure and effective retrieval strategies where recyclables can be collected and used as raw material in the manufacturing processes. ${ }^{20}$ It is applicable to a vast range of materials, either for the production of similar product (recycled paper for low-grade paper production), other products manufacturing (manufacturing construction materials) or for energy conversion as in anaerobic digestion and composting. ${ }^{20}$ On the other hand, reuse practice means, utilizing a material or a product, can be done by repairing, selling or donating these items to charity and community groups. ${ }^{21}$ This is an advantageous strategy since it allows efficient use of waste, saves energy and water, reduces pollution, and lessens society's consumption of natural resources compared to the use of single-use products and materials. ${ }^{22}$ An ideal strategy for waste management is to prevent the generation of waste by reducing waste at source. Source reduction includes planning and execution of waste minimization right at the generation stage and is the most preferred option according to the waste management strategy. It focuses on reducing the volume and toxicity of waste generated as well as switching to reusable products and packaging. ${ }^{22}$

Apart from the government policy and campaign, the success of an efficient waste management system depends on public acceptance and participation. Environmental attitudes, behaviors, and participation are highly influenced by knowledge. Thus, there is a possibility to improve public consumption behavior if public environmental awareness is improved. ${ }^{23}$

\section{Islamic teachings on environmental health}

The Islamic teachings on environmental health and waste management could be observed from various teachings of Islam, including;

First, with regards to the hygienic lifestyle, to show the importance of being clean and hygienic, as reported by Imam al-Bukhari in his authentic collection, the Prophet (s. a. w.) mentioned that: "cleanliness/purification of half of faith (الطهور شطر

"الإيمان(This is to say that, about 50\% of the person's religious duty is to be clean and maintain a hygienic lifestyle, including body, clothes, house, mouth and other necessary aspects of cleanliness. Some scholars mentioned that the reward for purification is so great that it could reach a level in reward equal to half of that for having faith.

Second, in another narration, to show the importance of hygienic lifestyle, the Prophet (s. $a$. w.) counted the act of cleaning trashes and health risking materials from the roads and streets, so that its environmental health is maintained, among the seventy branches of faiths (Iman). As reported by Imam Muslim in his authentic collection, the Prophet (s. a. w.) said: "There are some seventy branches of faith. The highest is to bear witness that 'There is no god but Allah and Muhammad is the Messenger of Allah'; the lowest is the removal of harm or waste materials from the road."

$$
\begin{aligned}
& \text { "الإممان بضعٌ وسبعون أو بضعٌ وستون شُعْبة، فأفضلُها قولُ: لا إله إلا الله، وأدناها إماطة } \\
& \text { الأذى عن الطريق، والحياء شُعْبة من الإيمان." }
\end{aligned}
$$

Third, in another narration, to prevent health complications that might arise from consuming or using contaminated water, and perhaps to maintain environmental health, the Prophet (s. $a . \quad w$.) prohibited the urination on standing or static water. He said: “活.e., none of you should urinate in standing water." The prohibition of urinating in water that does not flow includes ponds, water reservoirs, pools, and sources from which people take their drinking water. 
Fourth, part of the Islamic teaching on environmental health is to avoid urination or passing motion on the roads, public places or under the trees which people use as a shelter during hot seasons. On one occasion he said: "Avoid three curses: passing motion/stole in resources, on the road or in the shadow of the tree that is used as a shelter." (اتقوا الملاعن الثلاث: البراز في الموارد وقارعة الطريق والظل)On another occasion, the Prophet (s. a. w.) prohibited passing motion of the shadow of the tree that is used as a shelter as well as on the sides of the river فى عن قضاء الحاجة تحت الأشجار المثمرة، وضفة النهر الجاري

Fifth, there are other narrations reported on the authority of the Prophet (s. a. w.) related to the preservation of the environment, particularly regarding the issues of agriculture, land cultivation, irrigation and water distribution, as well as the prohibition of deforestation and the maltreatment of animals.

Sixth, the Islamic attitude towards environmental health teaches the principle that the natural environment is not evil but neutral and good (sālih) in itself. However, man's attitude towards the natural resources and the environment includes the behaviour of being reckless and careless, which might lead to an unhealthy environment. The natural environment functions in accordance with natural laws, which are firmly perfected (wa wada'a al-mizān) by the divine power of Almighty, Allah (s. w. t.). In chapter 55, verses 7-10, the Qur'an "demonstrates that everything in the universe was created to operate with a unified purpose and that each element is critical to maintain the balance and functioning of the universe." This balance and perfection of nature can be observed in every aspect of nature, including the physical order of the universe, in biology, in chemistry, and many other fields. ${ }^{24}$ For instance, "this perfect balance can be seen from the examination of any component of the universe, including the Earth's ability to clean itself. Despite the amount of waste produced from animals, as well as the deaths of species, the earth has the ability to clean itself, to the point that this death and waste is not even visible. The death and waste products of the species living in the oceans should mean the oceans do not have any clean water, yet the perfect balance created by God means that clean water is maintained, allowing the ecosystems to function perfectly. The balance of creation is so detailed that the reproduction rate of species changes according to lifespan; species with higher reproduction rates have shorter lifespan and vice-versa".

Seventh, to use natural resources for man's consumption is permitted as long as there is no wasteful behaviour towards nature. In chapter 7, verse 31, the Qur'an states "eat and drink: But waste not by excess, for Allah loveth not the wasters." While in chapter 17, verses 26-27, the Qur'an associates the wasteful attitudes with ungrateful desires that lead to evil ends and thus commands "but squander not (your wealth) in the manner of a spendthrift. Verily spendthrifts are brothers of the Evil Ones; and the Evil One is to his Lord (himself) ungrateful." Islam prohibits wasteful behaviour and the culture of exceeding the limits of normality in consumption. In the meantime, it promotes the culture of moderation in consumption. The Qur'an praises the behaviour of "those who, when they spend, are not extravagant and not niggardly, but hold a just (balance) between those (extremes)." (the Qur'an, 25:67).

\section{CONCLUSION}

As illustrated in the above-mentioned hadith and the Qur'anic verses sustainable environmental health have a significant place in the Islamic teachings, which emphasized on cleanliness, hygienic lifestyle and moderation of consumption. In chapter 30, verse 41, the Qur'an mentions that the natural balance of the natural environment is endangered as a result of environmental degradation activities and wasteful behaviour of man, whereby the Qur'an states that; “corruption has appeared throughout the land and sea by (reason of) what the hands of people have earned so He may let them taste part of (the consequence of) what they have done that perhaps they will return (to righteousness)". This teaching ideally should shape a more responsible and eco-conscious Muslim. In fact, the integration of the above mentioned Islamic values towards achieving environmental health could be an effective and comprehensive solution to the current problem in waste management that is caused by irresponsible attitudes and culture exhibited by a man in many parts of the world.

\section{REFERENCES}

1. Agamuthu P, DennisV. Policy trends of extended producer responsibility in Malaysia. Waste Manag Res , 2011; 29: 945.

2. Agamuthu P, Fauziah SH. Challenges and issues in moving towards sustainable landfilling in a transitory countryMalaysia.Waste Management and Resources, 2011; 29:13-19. http://dx.doi.org/10.1177/0734242X1038308 0

3. Ministry of Housing and Local Government. Strategic Solid Waste Management: The Malaysian Approach. Keynote address by Secretary General of Ministry of Housing and Local Government Malaysia at the Second Meeting of the Regional 3R forum, 4th October 2010, at Sunway Hotel Resort and Spa, Kuala Lumpur.

4. Hoornweg, Daniel \& Bhada-Tata, Perinaz. What a Waste : A Global Review of Solid Waste Management. Urban development series; Knowledge papers no. 15, 2012. World Bank, Washington, DC. (c) World Bank. Available at : 
https: / /openknowledge.worldbank.org/handl e/10986/17388 License: CC BY 3.0 IGO.

Accessed November 13, 2016

5. Subhan M, Ghani ABA, Joarder MHR. Urban Community Willingness to Pay for Improved Solid Waste Management in Malaysian Municipality: A Choice Modeling Approach. Asian Social Science, 2014; 10:122.

6. Mian MM, Zeng X, Nasry AANB, Al-Hamadani $S M$. Municipal solid waste management in China: a comparative analysis. Journal of Material Cycles and Waste Management. 2016:1-9.

7. Muzammil A, Miandad R, Waqas M, et al. Solid waste management in Saudi Arabia: A review. Journal of Applied Agriculture and Biotechnology. 2016; 1:13-26.

8. Azlina AH, Anees A, Mahamad HI, Nik NNAR. Food Waste Management in Malaysia- Current situation and future management options. Journal of Industrial Research \& Technology. 2012; 2:36-39.

9. Jereme, I.A., Siwar, C., Begum, R.A., and Abdul Talib, B. Addressing the problems of food waste generation in Malaysia. International Journal of Advanced and Applied Science, 2016; 3:68-77.

10. Robinson BH. E-waste: an assessment of global production and environmental impacts. Science of Total Environment. 2009; 408:18319

11. Needhidasan S, Samuel M, Chidambaram R. Electronic waste-an emerging threat to the environment of urban India. Journal of Environmental Health Science and Engineering, 2014; 12: 1.

12. Hultman J. and Corvellec $\mathrm{H}$. The European Waste Hierarchy: from the sociomateriality of waste to a politics of consumption. Environ. Planning-Part A, 2012; 44: 2413-2427 http://dx.doi.org/10.1068/a44668

13. Dijkgraaf E, Vollebergh HRJ. Burn or bury? A social cost comparison of final waste disposal methods. Ecol. Econ., 2004; 50: 233-247.

14. Ebenstein $\mathrm{A}$. The consequences of industrialization: evidence from water pollution and digestive cancers in China. Review of Economics and Statistics, 2012; 94:186-201

15. Elizabeth B, Menon, M. Seasonal Effects of Water Quality: The Hidden Costs of the Green Revolution to Infant and Child Health in India. Journal of Development Economics 2014; 107: 49-64.

16. Nelms SE, Duncan EM, Broderick AC, et al. Plastic and marine turtles: a review and call for research. ICES Journal of Marine Science: Journal du Conseil, 2015; fsv165.

17. Hu S, Shy CM. Health effects of waste incineration: a review of epidemiologic studies. J. Air Waste Manage. Assoc; 2001; 51: $1100-9$

18. Harrard SJ, Harrison RM. The Health Effects of the Products of Waste Combustion. Birmingham, UK: Institute of Public and
Environmental Health, University of Birmingham.1996.

19. Agency for Toxic Substances and Disease Register (ATSDR). Hazardous Substances Emergency Events Surveillance. Annual report. Atlanta: US Department of Health and Human Services, Public Health Service. 1995.

20. Pariathamby A, Fauziah SH. Sustainable $3 R$ practice in the Asia and Pacific Regions: the challenges and issues. In Pariathamby A, Tanaka M, eds, Municipal Solid Waste Management in Asia and the Pacific Islands (pp. 15-40). Springer Singapore.2014

21. Samiha B. The importance of the $3 R$ principle of municipal solid waste management for achieving sustainable development. Mediterranean Journal of Social Sciences, 2013; 4: 129.

22. Johari A, Alkali H, Hashim H, Ahmed SI, Mat R. Municipal solid waste management and potential revenue from recycling in Malaysia. Modern Applied Science, 2014; 8: 37

23. Haron SA., Paim L, Yahaya, N. Towards Sustainable Consumption: An Examination of Environmental Knowledge among Malaysians. International Journal of Consumer Studies. 2005; 29: 426-436.

24. Hashi, AA. Bioethics: A comparison Study of its Concept, Issues and Approaches. Kuala Lumpur: IIUM Press. 2015 